\title{
Exploring the Impact of Wind Loads on Tower Crane Operation
}

\author{
Lianghai Jin, ${ }^{1,2,3,4}$ Han Liu $\mathbb{D}^{1,2}$ Xiazhong Zheng, ${ }^{1,2,3,4}$ and Shu Chen $\mathbb{D}^{1,2,3,4}$ \\ ${ }^{1}$ Hubei Key Laboratory of Construction and Management in Hydropower Engineering, China Three Gorges University, \\ Yichang 443002, China \\ ${ }^{2}$ College of Hydraulic \& Environmental Engineering, China Three Gorges University, Yichang 443002, China \\ ${ }^{3}$ China Three Gorges University and Anhuan Technology Co., Ltd., Yichang 443002, China \\ ${ }^{4}$ Safety Production Standardization Evaluation Center, China Three Gorges University, Yichang 443002, China
}

Correspondence should be addressed to Han Liu; 316960917@qq.com and Shu Chen; chenshu@ctgu.edu.cn

Received 12 March 2020; Revised 25 June 2020; Accepted 1 July 2020; Published 31 July 2020

Academic Editor: Andras Szekrenyes

Copyright (c) 2020 Lianghai Jin et al. This is an open access article distributed under the Creative Commons Attribution License, which permits unrestricted use, distribution, and reproduction in any medium, provided the original work is properly cited.

The construction industry continues to be one of the industries with the highest accident rate. Tower cranes have always been the central component of many construction operations. With recent advancements in tower cranes, more efforts have been made for their safe operation. The impact of natural environmental factors on the operation of tower cranes cannot be ignored, especially the impact of the wind load, which can be found in construction regulations worldwide. Therefore, a large number of recent studies have focused on exploring different approaches to improving the impact of loads, such as improved feedback controllers and collocated sensors. However, there are few studies on the impact of the flexible cable pendulum system under wind load. To quantify the impact in this paper, first, the swing model of the hanging and the model of sling fluctuation are proposed as the base. Second, the flexible cable pendulum model is designed for the impact of tower cranes under wind load. By field experiments, the applicability of the model in practical use is analyzed. A case of the Crane Beach Hydropower Station is investigated as a demonstration. With MATLAB programming, the variation in the hanging impulse with wind speed is shown, indicating that the maximum wind speed should be $12 \mathrm{~m} / \mathrm{s}$ if the factors that people can control are considered. When considering the factors that can be harmful to humans, the maximum wind speed is $17 \mathrm{~m} / \mathrm{s}$. With the proposed model, the impacts of wind load on tower crane operation can be quantified without actual deployment, offering a more straightforward quantitative tool for safe regulations and engineering management.

\section{Introduction}

Tall and flexible tower cranes are widely used at construction jobsites, and irregular oscillation of the hanging caused by the load is an important cause of tower cranes hitting people [1]. In addition, environmental wind is the major external disturbance source of hanging payloads [2], which leads to additional sway. Thus, wind is always considered when designing safety regulations of tower cranes [3]. In China, the general regulation is to stop the operations of tower cranes when the wind scale reaches a certain level (JGJ-2762012). However, the regulations are usually based on accident analysis, and sometimes the wind does not affect the operation of tower cranes, though they must be stopped because of the regulations. This setback results in less than optimal efficiency, higher costs, and longer deadlines. Additionally, some projects cannot stop construction halfway. Therefore, it is necessary to explore the maximum wind speed at which tower cranes can operate.

The crane system of the tower crane including the lifting rope and hanging is generally known as the flexible cable pendulum system. When a strong wind occurs, the movement of the flexible cable pendulum system may be affected [4]. Once the flexible cable pendulum system is affected, it will affect the movement state of the hanging, resulting in errors in landing [5]. The inaccurate location of the landing may lead to construction errors and engineering problems. Even more seriously, it may hit construction personnel and cause safety accidents [6]. Therefore, the motion of the flexible cable pendulum system under horizontal wind loads 
should be studied. This can provide the basis for the limit of the wind scale when the construction must stop for safety management. In this manuscript, the movement of the flexible cable pendulum under a horizontal wind load is tried to be explored.

The first step in exploring the movement is to analyze the movement of the lifting rope and the hanging of the tower crane under wind loads. For a movement of the flexible cable pendulum system of the tower crane, the status constraint conditions would vary in different situations. For example, because different tower cranes have different rope lengths, the movements of the flexible cable pendulum systems would be different even if the same wind load is encountered. Therefore, the length of the rope is an influential factor that affects the movement of the flexible rope under wind loads. For example, a very heavy hanging is much less affected by wind loads than a light hanging. Therefore, not only the length of the rope but also the mass of the hanging should be considered in the model. Thus, these possible impact factors should be fully considered in the modeling process.

In this paper, the movement of a flexible cable pendulum under wind loads is investigated, considering different wind speeds. To quantify the impact of wind on tower cranes, a mathematical model of the flexible cable pendulum wave under the mixed initial boundary conditions is proposed based on the string wave equation because it is impractical to conduct a real field test for every wind speed. By conducting the mathematical model, different wind speeds can be represented in detail by a set of numerical values, including the coordinate value of the flexible pendulum system, force situation, and rope form.

The remainder of this paper is organized as follows. First, the high number of injuries from tower cranes in construction is reviewed, and the impact of wind load on tower cranes and some improvement methods are discussed. Second, the model of the flexible cable pendulum and algorithm optimization are presented. Third, a case of the Crane Beach Hydropower Station is presented and analyzed. Fourth, the findings and limitations of the study are discussed. Finally, the conclusions are summarized.

\section{Background and Related Work}

High injury and fatality rates have continuously been observed in the construction industry. Although the number of accidents in construction has decreased recently, construction is still considered one of the most dangerous industries [7]. Tower cranes are the central component of many construction operations and are associated with a large fraction of construction deaths $[8,9]$. Mucenski et al. analyzed 212 nonfatal injuries in the work process. Research has shown that trucks and tower cranes are the riskiest machines. "Struck by an object," "struck against," "caught in, under or between," and "fall to level below" are the most common forms of injury that occur when using construction machinery and tools [10]. Therefore, research on the safety of tower cranes is helpful to reduce the occurrence of construction accidents. Currently, research on tower cranes mainly focuses on lifting plan optimization $[11,12]$, optimizing the location of tower cranes [13, 14] and the safety of tower cranes. Due to its structure, the tower crane will collapse when the load is too large. Tower cranes have been the subject of research investigations to reduce the swaying of the load for several decades [15]. Tower crane loads exhibit unwanted motions such as swings, twists, and bounces that cause safety hazards and decrease performance. Numerous controllers have been developed to reduce load swing, and Yoon et al. presented a method for generating commands to suppress the oscillations [16]. Vaughan et al. [17] reviewed a command generation technique to suppress the oscillatory dynamics with robustness to frequency changes, and performance improvements occurred during both local and teleoperated control.

Tower crane operation platforms are distant from the ground, and it is very difficult for the driver to accurately visually control the construction machinery location and the location of workers on the ground. The potential collisions in the operating environment depend on the location and movement information of the tower crane signalman macroscopic observations [18]. However, human observational error is one of the causes of tower crane safety accidents $[19,20]$. Chen and Luo [21] considered the accuracy features of the localization system and the constraint for decision making and then proposed the precision and recall evaluation model of position-related safety status decision making. Luo et al. [22] improved emerging sensing technologies that offer a solution to improve jobsite safety performance by providing location information to determine a worker's safety situation regarding proximity to dangers. Yang et al. [23] established an automatic collection, analysis, and early-warning system that can help improve the safe operation of tower cranes. Using the linear approximant, a dynamic measurable output multidelay controller for independent control of the performance outputs of the system is proposed [24]. This system can be used for the signal detection of tower cranes. To improve the blind spots, Lee et al. [25] introduced a newly developed tower crane navigation system that provides three-dimensional information about the building and surroundings as well as the position of the lifted object in real time using various sensors and building information modeling (BIM). Cheng and Teizer [26] presented an approach that aims to increase the situational awareness of tower crane operators by aligning an enhanced understanding of the construction site layout with increased operator visibility of ground-level operations.

The current studies of tower cranes focus on human factor engineering. However, these studies underestimated external impacts such as environmental factors. In particular, the wind has a great impact on the hoisting operation of the tower crane [27]. Tower cranes are typically operated at considerable heights; their slewing reducer has to support both the variable wind loads at those heights and the load results from the inertia of the system [28]. In addition, uncertain disturbances such as environmental wind always degrade the control performance of the crane system. Seoul, the research area, has the fastest wind speed in April and the slowest in October. This hosting time estimation model would be used for estimating the impact of wind [29]. In 
many countries, "wind speed of $20 \mathrm{~m} / \mathrm{s}$ " is normally used as the maximum in-service wind speed for tower cranes. Therefore, the investigation of the proper wind speed for regulation would be helpful to secure the safety of tower crane operation under windy conditions [30].

To reduce the impact of environmental wind, many studies have focused on improving the design of control systems for tower cranes. Miranda-Colorado and Aguilar presented a methodology for designing controllers that attenuate the load swing angle in two-dimensional overhead crane systems with varying rope lengths [31]. El Ouni et al. proposed a smart tower crane equipped with pairs of collocated sensors and actuators to mitigate turbulent wind [32]. Sun et al. proposed an improved feedback controller with an elaborately constructed integral term [33]. Although many improvements have been made, our regulations and field safety management still require the most common regulations. This requirement means knowing exactly the wind speed that makes the tower crane stop working.

\section{Methodology}

The flexible cable pendulum system consists of a hoist, a sling, and a hanging. The mathematical model of the flexible cable pendulum system is difficult to establish because of its multi-degree-of-freedom, multiobjective, and multibody system. To facilitate our research, we assume that the swing component of the suspension movement of the cable is independent of the sling fluctuation component and that it obeys the superposition principle [34]. For the swing of the hanging, according to the different ways of representing the swinging angle, the swinging angle can be divided into the pendulum model [35], which represents the swinging angle with spherical coordinates, and the space ball model [36], which represents the swinging angle with internal and external angles.

Based on the motion characteristics of the cable crane flexible cable pendulum system, an absolute coordinate $O x_{0} y_{0} z_{0}$ was built. The $x_{0}$-axis points to the boom in the horizontal plane; the $y_{0}$-axis points to the right side of the boom; and the $z_{0}$-axis points straight down. The Oxyz coordinate system is established according to the movement track of the suspended object in the horizontal plane. In $O x y z$, the $X$-axis coincides with straight line $O A$, and the direction close to the boom is set as positive. The $Z$-axis is still going straight down. As shown in Figure 1, when the angle between $O x$ and $O x_{0}$ is $\alpha$, the coordinates $O x y z$ and $O x_{0} y_{0} z_{0}$ can be freely transformed by the following transformations:

$$
\left[\begin{array}{l}
x_{0} \\
y_{0} \\
z_{0}
\end{array}\right]=\left[\begin{array}{ccc}
\cos \alpha & -\sin \alpha & 0 \\
\sin \alpha & \cos \alpha & 0 \\
0 & 0 & 1
\end{array}\right]\left[\begin{array}{l}
x \\
y \\
z
\end{array}\right] .
$$

As shown in Figure 1, the motion parameters of the hanging and its rope are set as follows: point $A$ represents the head of the sling and oscillates at origin $O ; m$ is the mass of the hanging. Based on the spherical coordinates established in the figure, $L$ is the length of the hanging rope; $x(t)$ is the

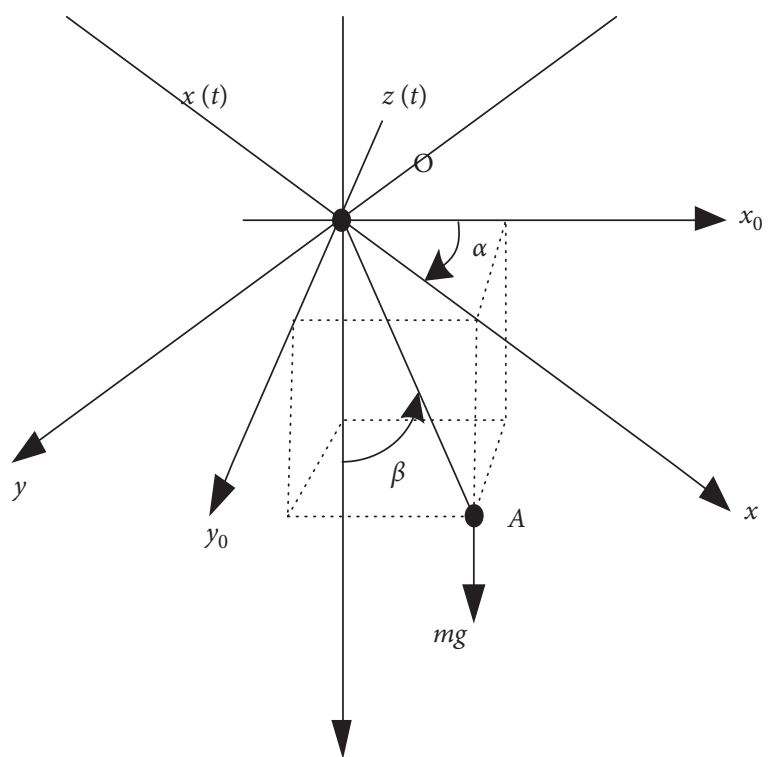

Figure 1: Structural analysis diagram of the flexible cable pendulum systems.

decomposed displacement of the hanging head in the $X$-axis direction; and $z(t)$ is the displacement of the hanging head in the $Z$-axis direction. However, the rope of the cable crane is usually rigid, and we can ignore the displacement in the $Z$ axis direction.

3.1. Model of the Swing of Hanging. Since the movement of the hanging in the $X$-axis direction is only affected by the horizontal force, the displacement of the hanging head is proportional to the force exerted and always points to the equilibrium position. The motion state is the same as that in which the hanging is in simple harmonic motion. Therefore, assuming that the movement of the hanging head in the $X$ axis direction is simple harmonic motion, the displacement along the $X$-axis of the hanging head at $t$ is

$$
x(t)=U \cos (\omega t)
$$

where $U$ is the amplitude of simple harmonic motion, $\omega=$ $2 \pi / T_{A}$ is the angular frequency of hanging head motion, and $T_{A}$ is the movement period of the hanging head.

Taking the second derivative of (2), the acceleration of point $\mathrm{A}$ is

$$
x(t)^{\prime \prime}=-U \omega^{2} \cos \omega t .
$$

According to the pendulum principle, the swing equation of the hanging is obtained as

$$
\beta^{\prime \prime}+2 \xi \omega_{1} \beta^{\prime}+\omega_{1}^{2} \beta=2 \xi \omega_{1} \frac{x^{\prime}}{L}+\omega_{1}^{2} \frac{x}{L},
$$

where $\xi$ is the damping coefficient, $\omega_{1}$ is the natural frequency of the pendulum, $\beta$ is the angle between the hanging rope and the vertical direction, $\omega_{1}=\sqrt{g / L}$, and $g$ is the acceleration of gravity.

Substituting the above formula into (4), we get

$$
\beta=\Theta \cos (\omega t+\alpha) \text {, }
$$


where $\Theta$ is the swing angle amplitude,

$$
\begin{aligned}
\Theta & =\frac{U}{L}\left(1+d^{2}\right)^{1 / 2} G(\omega), \\
d & =2 \xi \frac{\omega}{\omega_{1}} \\
G(\omega) & =\left(\sqrt{\left[1-\left(\frac{\omega}{\omega_{1}}\right)^{2}\right]^{2}+d^{2}}\right)^{-1} .
\end{aligned}
$$

Taking the derivative of both sides of (5), the angular velocity of the swinging object can be obtained as

$$
\begin{aligned}
\beta^{\prime} & =-\omega \Theta \sin (\omega t+\alpha)=-\Theta^{\prime} \sin (\omega t+\alpha), \\
\Theta^{\prime} & =\omega \Theta=G_{1}(\omega) U, \\
G_{1}(\omega) & =\frac{\omega}{L}\left(1+d^{2}\right)^{1 / 2} G(\omega),
\end{aligned}
$$

where $\Theta^{2}$ is the angular velocity amplitude and $G_{1}(\omega)$ is the transfer function of the horizontal displacement of the lifting head in the $X$-axis direction on the swinging angular velocity of the hanging.

The additional tension value of the sling generated by the hanging head excited in the $X$-axis direction is

$$
F_{x}=m L \beta^{\prime 2} \text {. }
$$

The wind force of the hanging in the $X$-axis direction is

$$
F_{W}=W_{P} S \text {, }
$$

where $W_{P}$ is the wind pressure perpendicular to the direction of the airflow and $S$ is the surface area of the windward surface of the hanging.

$$
W_{P}=0.5 r_{0} \cdot v^{2}
$$

where $r_{0}$ is the air density and $v$ is the wind speed.

Therefore, according to the force analysis, the total tensile force of the sling is

$$
F=m g \cos \alpha+m l \beta^{\prime 2}+W_{P} S \sin \alpha .
$$

The horizontal acceleration formula of the hanging is

$$
a_{h}=\frac{F_{X}+F_{W}}{m} \text {. }
$$

3.2. Model of Sling Fluctuation. Let the horizontal displacement of each particle on the rope be $x=u(z, t)$.

As shown in Figure 2, the slope of the end of the sling can be represented by $\partial x / \partial z$ or $\tan (\pi-\eta)$, and $\eta$ is the angle between the sling tension $F$ and the negative direction of the $Z$-axis. According to Newton's laws of motion, the sling fluctuation equation is deduced as

$$
\left\{\begin{array}{l}
m \frac{\partial^{2} u}{\partial t^{2}}+F \sin \eta=0, \\
m g-F \cos \eta=0,
\end{array}\right.
$$

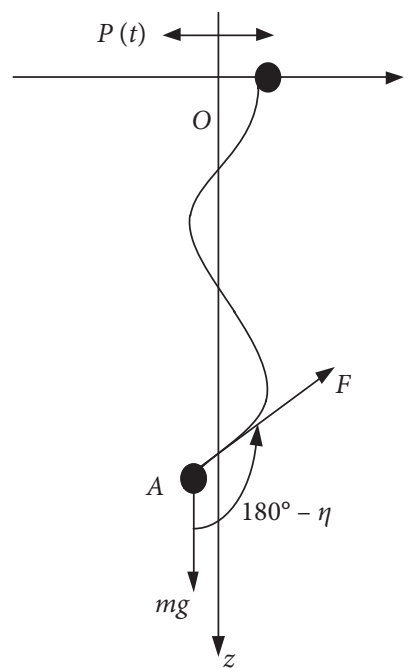

FIGURE 2: Rope fluctuations analysis of the flexible cable pendulum.

When $\eta$ is small, $\partial u / \partial z=-\tan \eta \approx-\sin \eta, \cos \eta \approx 1$ can be converted. Therefore, (13) can be transformed into

$$
\frac{\partial^{2} u}{\partial t^{2}}-g \frac{\partial u}{\partial z}=0
$$

According to the analysis of the swinging phenomenon of the hanging, the characteristic solution of (14) can be deduced as

$$
u(z, t)=B \sin \omega t \cdot \exp \left[\omega^{2}(z-N L)\right] .
$$

Here, $B$ is the amplitude, which depends on the situation; $B$ is the maximum swing amplitude of the hanging head here; and $N$ represents any integer, and this parameter can control the swing amplitude of the hanging.

Assuming that the sling is uniform, completely soft, and tensed in a straight line at equilibrium, we take the line as the $Z$-axis, and points on the sling are represented by points on the $Z$-axis. Suppose the sling undulates in a plane. The displacement of the sling point perpendicular to the $Z$-axis at time $t$ is represented by $u(z, t)$. For small vibrations, the swinging angle of the hanging is very small. When there is an external force on the sling per unit length, the external force density is $f(z, t)$, and when its direction is perpendicular to the $Z$-axis, we can obtain the nonhomogeneous string vibration equation:

$$
\frac{\partial^{2} u}{\partial t^{2}}-v^{2} \frac{\partial^{2} u}{\partial z^{2}}=f(z, t),
$$

where $v$ is the wind speed.

To ensure the uniqueness of the formula and its applicability in this case, the following mixed initial boundary conditions are set:

The initial conditions are

$$
\begin{aligned}
u(z, 0) & =\varphi(z), \\
\frac{\partial u}{\partial t}(z, 0) & =\phi(z),
\end{aligned}
$$


where $\varphi(z)$ and $\psi(z)$ are the initial values of the sling that need to be determined according to the specific initial requirement.

The boundary conditions are

$$
\begin{aligned}
& u(0, t)=\rho(t), \\
& u(L, t)=\sigma(t),
\end{aligned}
$$

where $\rho(t)$ defines the function for the vibration source:

$$
\rho(t)=a t^{2} \frac{E}{2},
$$

where $a$ represents the acceleration of the hanging head; $E$ is the adjustment factor, which is related to the nature of the simple pendulum system and the motion environment; and $\sigma(t)$ is the boundary condition of the swing of the hanging derived from (15).

$$
\sigma(t)=B \exp \left(\frac{-\omega^{2} L}{g}\right) \sin \omega t .
$$

3.3. Algorithm Optimization. If the partial differential equation is solved according to the standard function, there are too many discrete points and the value is not stable. To meet the stability of the calculation, as well as speed it up, the implicit difference method of unconditional stability is used to solve the partial differential equation of the sling wave. The specific calculation method is

$$
\begin{aligned}
& u_{i}^{0}=\varphi\left(z_{i}\right), \quad 1 \leq i \leq p-1 \\
& u_{i}^{1}=\varphi\left(z_{i}\right)+\tau \psi\left(z_{i}\right)+\frac{1}{2} \tau^{2}\left[a^{2} \varphi^{\prime \prime}\left(z_{i}\right)+f\left(z_{i}, 0\right)\right], \quad 1 \leq i \leq p-1, \\
& u_{0}^{k+1}=\rho\left(t_{k+1}\right) \\
& u_{p}^{k+1}=\sigma\left(t_{k+1}\right) \\
& {\left[\begin{array}{ccccc}
k_{0} & k_{1} & 0 & 0 & 0 \\
k_{1} & k_{0} & k_{1} & 0 & 0 \\
0 & \vdots & \vdots & \vdots & 0 \\
0 & 0 & k_{1} & k_{0} & k_{1} \\
0 & 0 & 0 & k_{1} & k_{0}
\end{array}\right]\left[\begin{array}{c}
u_{1}^{k+1} \\
u_{2}^{k+1} \\
\vdots \\
u_{p-2}^{k+1} \\
u_{p-1}^{k+1}
\end{array}\right]=\left[\begin{array}{c}
s^{2} \frac{\left(u_{0}^{k+1}+u_{o}^{k-1}\right)}{2}+2 u_{1}^{k}+\tau^{2} f\left(z_{1}, t_{k}\right) \\
2 u_{2}^{k}+\tau^{2} f\left(z_{2}, t_{k}\right) \\
\vdots \\
2 u_{p-2}^{k}+\tau^{2} f\left(z_{p-2}, t_{k}\right) \\
s^{2} \frac{\left(u_{p}^{k+1}+u_{p}^{k-1}\right)}{2}+2 u_{p-1}^{k}+\tau^{2} f\left(z_{p-1}, t_{k}\right)
\end{array}\right]-\left[\begin{array}{ccccc}
k_{0} & k_{1} & 0 & 0 & 0 \\
k_{1} & k_{0} & k_{1} & 0 & 0 \\
0 & \vdots & \vdots & \vdots & 0 \\
0 & 0 & k_{1} & k_{0} & k_{1} \\
0 \\
0 & 0 & 0 & k_{1} & k_{0}
\end{array}\right]\left[\begin{array}{c}
u_{1}^{k-1} \\
u_{2}^{k-1} \\
u_{p-2}^{k-1} \\
u_{p-1}^{k-1}
\end{array}\right] \text {, }}
\end{aligned}
$$

where $s=a \tau / h$ is the step ratio, $\tau$ is the time step, and $h$ is the spatial step. These represent the ratio of the length of the sling to the number of space intervals $p ; k_{0}=$ $1+s^{2}, k_{1}=-s^{2} / 2$,

$1 \leq k \leq n-1$, where $n$ is a discrete point; $u_{k}^{i}$ is the displacement $z_{i}$ of the point $i$ of the sling at time $t$; and $f\left(z_{i}, t_{k}\right)$ is the external force density. For the sake of research, we assume that the string fluctuations have no resistance, and $f\left(z_{i}, t_{k}\right)=0$.

Our assumption of the initial conditions is

$$
\varphi\left(z_{i}\right)=\varphi^{\prime \prime}\left(z_{i}\right)=\psi\left(z_{i}\right)=0 .
$$

Based on discrete point displacement on the sling due to the swing of the hanging, according to the swing angle $\alpha$ of the hanging, and the displacement coordinates of the $n$ discrete points in the coordinate system, Oxyz can be calculated.
The mathematical model calculation process of the cable crane flexible cable pendulum system is represented according to Figure 3.

\section{Case Study}

The Crane Beach Hydropower Station is the second largest hydropower station in China after the Three Gorges Hydropower Station. The biggest challenge in building the Crane Beach Hydropower Station is frequent gales. According to the statistical analysis of Crane Beach's wind rating measured for many years by the local meteorological department, the wind rating exceeds level 7 on approximately 241 days each year, and on many days the wind rating reaches level 10 .

A Kestrel 5500 weather meter is used to measure local wind speeds in real time. The field measurement picture is 


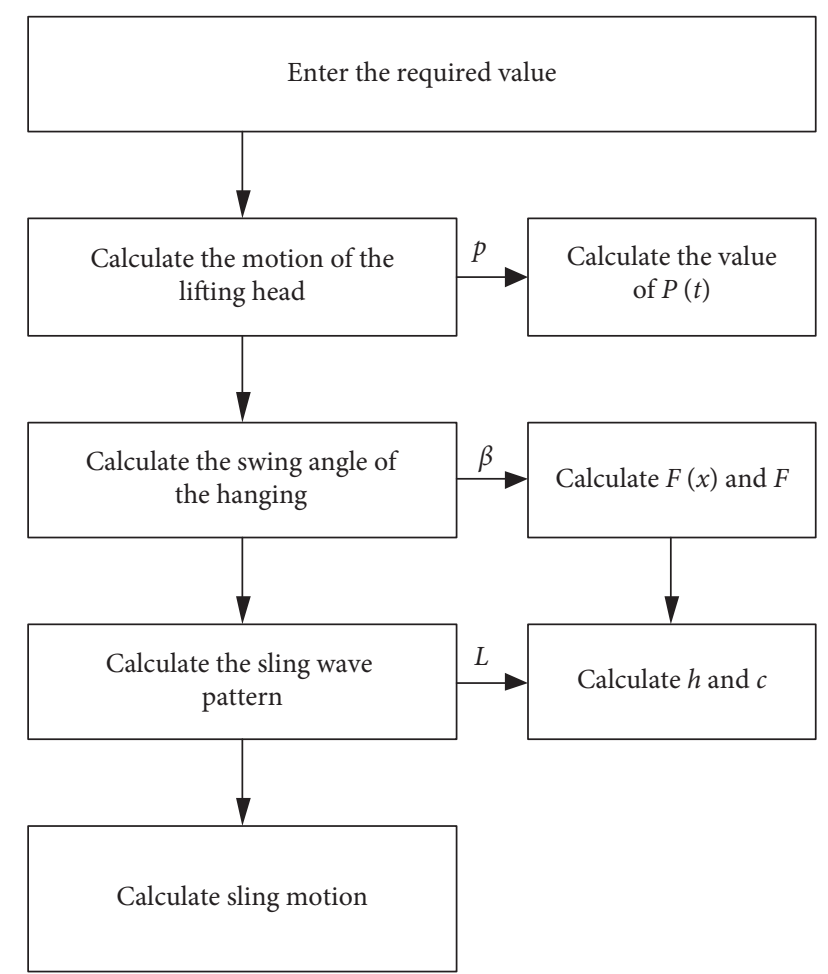

FIgURE 3: Flowchart of the flexible cable pendulum simulation.

shown in Figure 4. Then, we use the position detector of the tower crane to measure the distance of hanging. As long as the time interval is small enough, the acceleration we obtain can be approximated as the instantaneous acceleration at the current moment. Using this principle, we can compare the measured data with the calculated values to verify the feasibility of the model.

\section{Case Parameter}

The length of the on-site tower crane rope we used was $60 \mathrm{~m}$, the weight of the hanging was $6850 \mathrm{~kg}$, and the local air density was $1.293 \mathrm{~kg} / \mathrm{m}^{3}$. When lifting the hanging, the tower crane can rise or fall at a speed of $3 \mathrm{~m} / \mathrm{s}$. The measured wind speeds and the corresponding movement distances of the object are shown in Table 1.

\section{Results}

6.1. The Programming Calculation. By programming the flexible cable pendulum system model with MATLAB, the weight of the hoisting object was input to be $70000 \mathrm{~kg}$, the length of the hoisting rope was $70 \mathrm{~m}$, and the wind-facing surface area of the hoisting object was $5 \mathrm{~m}^{2}$, to obtain the fact that the force of the lifting rope varied with the wind speed. Then, the calculated data were imported into Origin 2018 to obtain Figure 5 of the change in the rope tension with wind speed.

The motion displacement diagram of the hanging in the flexible cable pendulum system with time is shown in Figure 6.
With the increase of wind speed, the horizontal impulse of the hanging increases is shown in Figure 7.

6.2. Model Validation. The data obtained from the above field experiment and the data derived from the model were tested by SPSS to verify the correctness of the model, and the results are as follows.(Table $2-4$ )

\section{Discussion}

Tower cranes are very complex mechanical systems that have been the subject of research investigations for several decades to reduce the swaying of the load, for example, wind load. Voisin et al. proposed an experimental method to study the behavior of tower cranes in strong winds and improved the design of the crane to reduce the crane overturning moments [37]. Eden et al. developed a method for selecting appropriate out-of-service design wind speeds for tower cranes [38]. In many countries, "wind speed of $20 \mathrm{~m} / \mathrm{s}$ " is normally used as the maximum in-service wind speed for tower cranes. In China, the hoisting safety regulations stipulate that operations must be stopped if the wind exceeds level six; the level six wind speed is between $10.8 \mathrm{~m} / \mathrm{s}$ and $13.8 \mathrm{~m} / \mathrm{s}$. Thus, the maximum in-service wind speed for tower cranes in China is $13.8 \mathrm{~m} / \mathrm{s}$. However, many projects were not stopped when wind speeds exceeded $13.8 \mathrm{~m} / \mathrm{s}$, and there were no safety incidents. Therefore, we need to explore the maximum wind speed allowed for tower crane construction, and the first step is to analyze the movement of cranes under wind loads.

First, the force on the rope as the wind speed changes is shown. It can be seen from Figure 5 that the force of the rope varies significantly with the wind speed and the tension of the rope is positively correlated with the wind speed. The higher the wind speed is, the steeper the trend of the rope tension is. This outcome means that the higher the wind speed is, the more difficult the rope is to control.

Second, the displacement of the crane over time when the wind speed is constant is represented. In Figure 6, the vertical direction is the displacement value of the hanging in the horizontal direction when the hanging is standing at the origin, the horizontal plane is the time value of $0-50 \mathrm{~s}$, and the perpendicular distance is the vertical height of the hanging. Since the force exerted on the flexible cable pendulum system is constant when the wind speed is constant, the motion of the flexible cable pendulum can be simplified to simple harmonic motion, which can also be easily seen in the figure.

Third, the variation in lifting impulse when the wind speed changes is explored. As shown in Figure 7, with the increase in wind speed, the hanging impulse increases significantly, and the higher the wind speed is, the greater the hanging impulse increases.

Then, the feasibility of the model in reality is verified. Through SPSS comparative analysis, the results of the model calculation and field experiment are shown in Tables 2-4. Table 4 shows that $t=0.897$. This value means that the model is 99 percent or more consistent with reality. The 


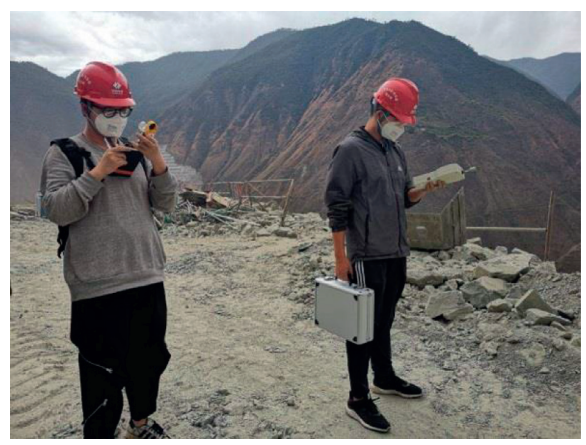

(a)

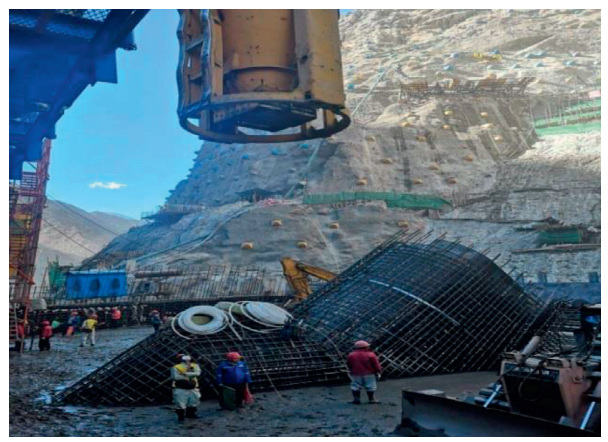

(b)

FIgURE 4: Field experiment picture.

TABLE 1: The measured wind speeds and the corresponding movement distances.

\begin{tabular}{lccc}
\hline Wind speed $(\mathrm{m} / \mathrm{s})$ & Run time $(\mathrm{s})$ & Run distance $(\mathrm{m})$ & The acceleration $\left(\mathrm{m} / \mathrm{s}^{2}\right)$ \\
\hline 9.12 & 1 & 0.325 & 0.325 \\
9.22 & 1 & 0.338 & 0.338 \\
9.16 & 1 & 0.328 & 0.328 \\
9.08 & 1 & 0.320 & 0.320 \\
9.11 & 1 & 0.322 & 0.322 \\
9.18 & 1 & 0.332 & 0.332 \\
9.15 & 1 & 0.328 & 0.328 \\
9.20 & 1 & 0.335 & 0.335 \\
9.13 & 1 & 0.324 & 0.324 \\
9.14 & 1 & 0.326 & 0.326 \\
9.21 & 1 & 0.336 & 0.336 \\
9.20 & 1 & 0.335 & 0.335 \\
\hline
\end{tabular}

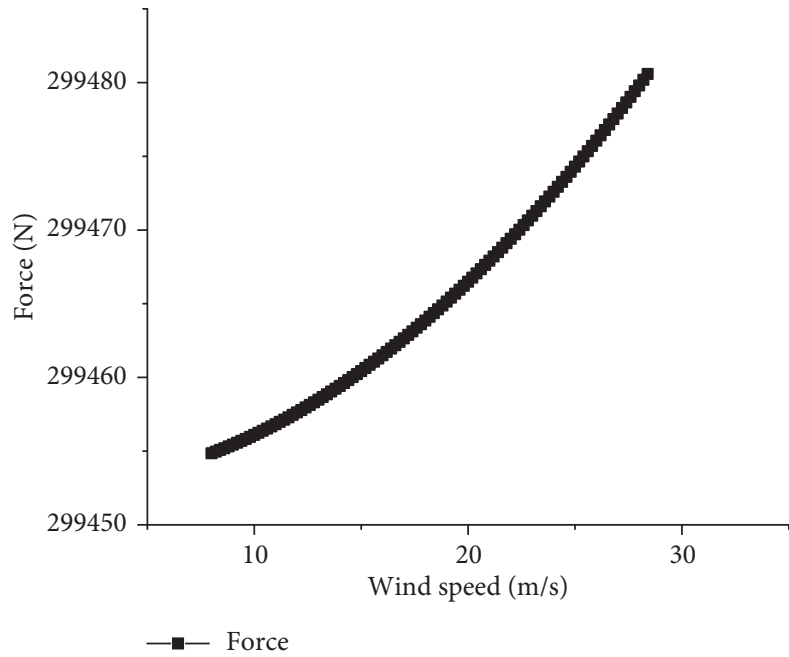

(a)



(b)

Figure 5: (a) Force on the sling when starting to lift. (b) Force on the sling when landing.

determination of this correlation can also verify the usability of the model in practical engineering. The correctness of the test indicates the applicability of the model.

When the hanging collides with a human body, the common collisions are as follows: the collision between the hanging and chest, the collision between the hanging and abdomen, and the collision between the hanging and legs.
Since the volume of the hanging is generally larger, and the hanging and the ground generally maintain a distance, the collision between the hanging and legs is not considered [39]. Compared with the chest, the abdomen is more vulnerable to injury because the abdominal bone structure protects less abdominal viscera, and internal organs are more likely to deform in front and side impacts, resulting in 


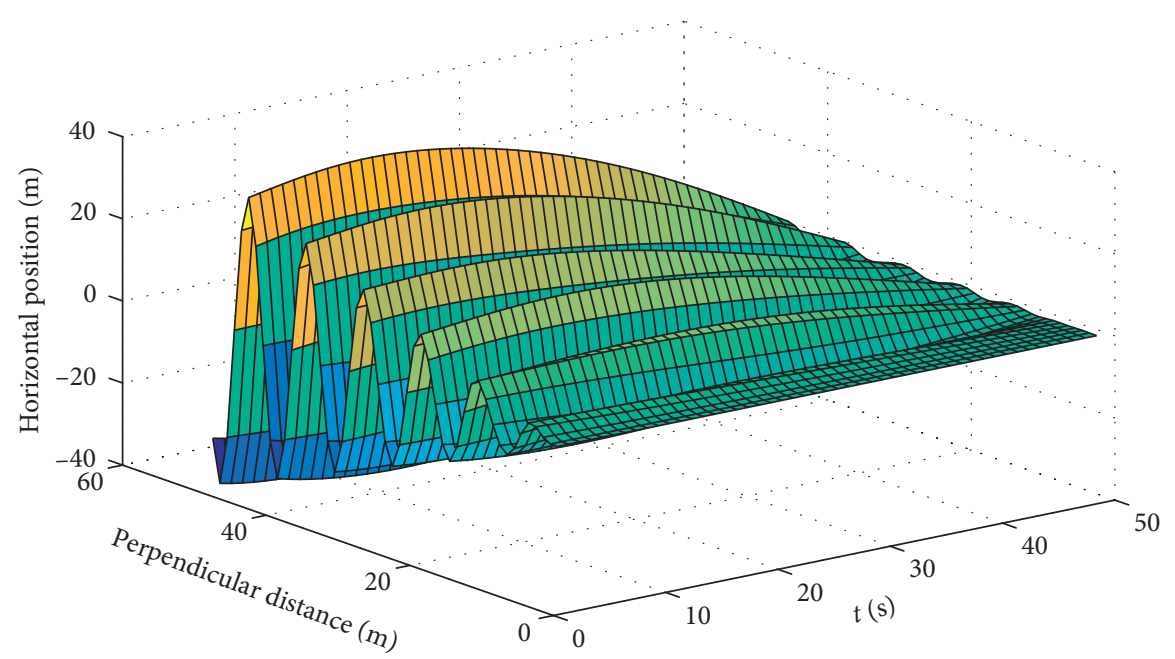

FIGURE 6: The motion displacement diagram of the hanging in the flexible cable pendulum system with time.

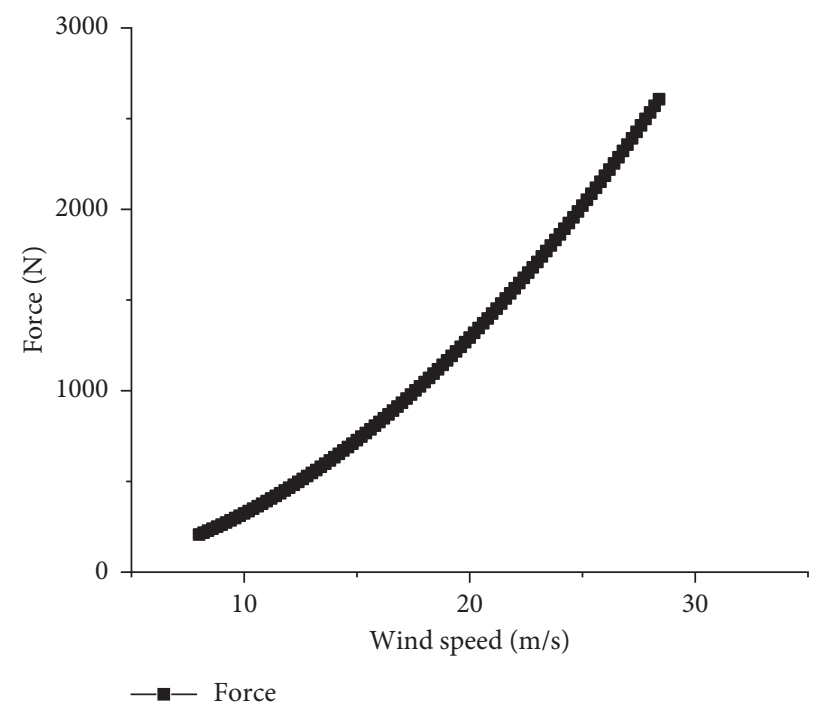

Figure 7: The horizontal direction of increase impulse with the increase of wind speed.

TABLE 2: Sample statistics.

\begin{tabular}{lcccc}
\hline & Average & Case number & Standard deviation & Mean of standard error \\
\hline Field experiment & 0.52908 & 12 & 0.005977 & 0.001725 \\
Model calculation & 0.52933 & 12 & 0.006344 & 0.001831 \\
\hline
\end{tabular}

TABle 3: Sample correlation coefficient.

\begin{tabular}{lcccc}
\hline & Case number & Correlation & Significance \\
\hline Field experiment \& model calculation & 12 & 0.989 & 0.000 \\
\hline
\end{tabular}

TABLE 4: Sample test.

Paired difference

\begin{tabular}{lccccccc} 
& Average & $\begin{array}{c}\text { Standard } \\
\text { deviation }\end{array}$ & $\begin{array}{c}\text { Mean of standard } \\
\text { error }\end{array}$ & $\begin{array}{c}\text { Difference 95\% } \\
\text { confidence interval } \\
\text { Lower } \\
\text { limit }\end{array}$ & Ceiling & $\begin{array}{c}\text { Degrees of } \\
\text { freedom }\end{array}$ & $\begin{array}{c}\text { Sig. } \\
\text { Field experiment \& model } \\
\text { calculation }\end{array}$ \\
\hline
\end{tabular}


TABLE 5: The congruent relationship of wind scale and wind speed.

\begin{tabular}{lcccccc}
\hline Wind scale & 5 & 6 & 7 & 8 & 10 \\
\hline Wind speed $(\mathrm{m} / \mathrm{s})$ & $8.0-10.7$ & $10.8-13.8$ & $13.9-17.1$ & $17.2-20.7$ & $20.8-24.4$ & $24.5-28.4$ \\
\hline
\end{tabular}

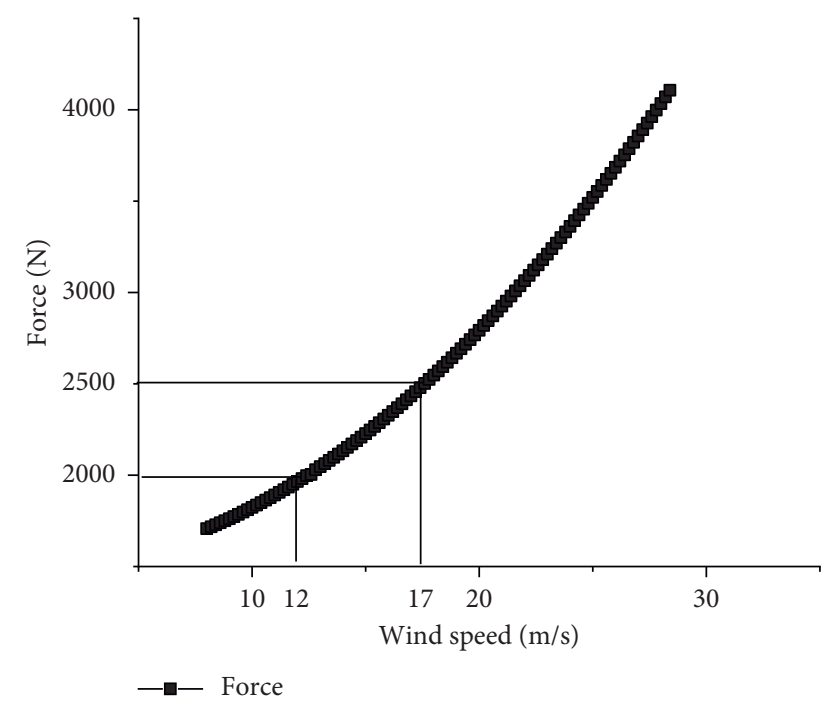

FIGURE 8: The relationship between the appropriate working wind speed and the hanging impulse.

vascular rupture and internal tissue damage [40]. The damage standard in China's automobile collision protection regulations (GB 20071-2006) can also be applied here. The peak force on the chest should be less than or equal to $3.3 \mathrm{kN}$, and the force peak on the abdomen should be less than or equal to $2.5 \mathrm{kN}$. In addition, the force that an adult man can control is generally $2 \mathrm{kN}$ [41]. Therefore, through these limits, we can find the wind speed suitable for tower crane construction. The relationship between the appropriate working wind speed and the hanging impulse is shown in Figure 8.

As shown in Figure 8, when the wind speed is more than $12 \mathrm{~m} / \mathrm{s}$, it has exceeded the maximum force controlled by ordinary auxiliary workers, while when the wind speed is more than $15 \mathrm{~m} / \mathrm{s}$, it has been determined that the collision will cause damage to auxiliary workers. Thus, the tower crane hoisting operation regulation in China (JGJ-276-2012) that states that tower crane operation must stop at a wind level greater than 6 (wind speed exceeding $10.8 \mathrm{~m} / \mathrm{s}$ ) is unwarranted, and the modified tower crane operation wind speed limit of $15 \mathrm{~m} / \mathrm{s}$ in South Korea [30] at which work must stop is inaccurate based on investigating the shutdown of most construction sites in Seoul. Therefore, if the accuracy of construction is considered, when the wind speed is more than $12 \mathrm{~m} / \mathrm{s}$, the tower crane should stop working; when the wind speed is more than $17 \mathrm{~m} / \mathrm{s}$, construction must be stopped because it will cause injury to the auxiliary construction personnel.

Finally, the improvement method is proposed according to the hoisting operation regulations of China. In China, the different wind speeds are expressed in terms of the wind scale. According to the congruent relationship of wind scale and wind speed in Table 4, the regulations on hoisting operation safety in China could be modified as follows: (1) if lifting operations require high construction precision, the construction should be stopped when the wind force is more than level 6; (2) if the construction precision requirements for lifting operations are not so high, then when the wind force is more than level 8, operations must shut down.

\section{Conclusions}

The effects of the wind load on tower crane operation are investigated in this paper because wind speed limits are often mentioned in the tower crane work safety regulations and vary from country to country. However, it is not accurate to consider only the impact of wind load on the movement of the hanging. Considering the features of tower crane operation, a motion model of the flexible cable pendulum system under wind load is proposed. To sum up, the two primary contributions are as follows.

A simple harmonic motion-based flexible cable pendulum system model is proposed. The key point is to establish the motion model of the flexible pendulum and obtain the impulse change in the hanging with the change in wind speed. It is impractical to conduct field experiments on the motion of the hanging at each wind speed. Therefore, we used the Kestrel 5500 weather meter and positioning device to measure the data over a period of time to verify the feasibility of the model. The results of field experiments show that the flexible cable pendulum system model has a good effect.

The model of the flexible cable pendulum system includes the swing model of the hanging and the swing model of the sling fluctuation, and the model considers not only the change in wind speed but also the change in time from lifting to landing.

In considering the crane safety regulations of China and South Korea, the safety regulations of the two countries have obvious differences. By using the established model and the data obtained through programming calculation, the reasons for the differences between the two countries can be explained. The two specifications are from different perspectives, but both of them make sense.

In summary, the effect of the wind load is focused on the flexible cable pendulum system of the tower crane rather than on the hanging. It is a good way to superimpose the swing model of the hanging and the swing model of the sling fluctuation with the principle of superposition, so that the model of the flexible cable pendulum can simulate the operation of all kinds of tower cranes. However, the model can only simulate the impact when the wind speed changes at a certain time and cannot be expressed when the time and the wind speed change at the same time. Thus, although it can be used as a basis for some regulations, the results may differ from the actual situation. Conversely, the original intention of this study is to provide support for the 
formulation of regulations. However, using the flexible pendulum model based on string dynamic theory can also be used to evaluate the proposed regulations. Future research based on the proposed model can not only consider the risk of human collision but also explore the possibility of damage to equipment caused by collision.

The data obtained from field experiments can verify the applicability of this model. The model can well reflect the movement of the hanging under different wind speeds and the fluctuation patterns of the sling cables at different times, and it presents the limiting wind speed which can be used as a reference for the establishment of safe regulations and engineering management regulations. Thus, the proposed model is significant for management in the construction industry.

\section{Data Availability}

The data used to support the findings of this study are included within the article.

\section{Conflicts of Interest}

The authors declare that they have no conflicts of interest regarding the publication of this paper.

\section{Authors' Contributions}

J. L. and L. H. were responsible for conceptualization; L. H., performed methodology; L. H., provided software; J. L., C. S., and Z. X., performed validation; J. L., performed investigation; C. S. and Z. X., provided resources; Z. X., performed data curation; L. H., wrote the original draft; L. H., performed review and editing; L. H., was responsible for visualization; J. L., supervised the study; C. S., performed project administration; and J. L. and C. S., were responsible for funding acquisition. All authors have read and agreed to the published version of the manuscript.

\section{Acknowledgments}

This research was funded by Open Fund of Hubei Key Laboratory of Construction and Management in Hydropower Engineering (China Three Gorges University) in 2019, grant no. 2019KSD05, and by National Natural Science Foundation of China, grant no. 51878385 .

\section{References}

[1] A. A. Marquez, P. Venturino, and J. L. Otegui, "Common root causes in recent failures of cranes," Engineering Failure Analysis, vol. 39, pp. 55-64, 2014.

[2] T. Ho, K. Suzuki, M. Tsume, R. Tasaki, T. Miyoshi, and K. Terashima, "A switched optimal control approach to reduce transferring time, energy consumption, and residual vibration of payload's skew rotation in crane systems," Control Engineering Practice, vol. 84, pp. 247-260, 2019.

[3] Z. Sun, N. Hou, and H. Xiang, "Safety and serviceability assessment for high-rise tower crane to turbulent winds," Frontiers of Architecture and Civil Engineering in China, vol. 3, no. 1, pp. 18-24, 2009.
[4] B. Ren, A. Leung, J. Chen, and X. Luo, "A hybrid control mechanism for stabilizing a crane load under environmental wind on a construction site," Computing in Civil Engineering, vol. 2015, pp. 499-506, 2015.

[5] I. J. Shin, "Factors that affect safety of tower crane installation/ dismantling in construction industry," Safety Science, vol. 72, pp. 379-390, 2015.

[6] S. Hwang, "Ultra-wide band technology experiments for realtime prevention of tower crane collisions," Automation in Construction, vol. 22, pp. 545-553, 2012.

[7] Y. Niu, W. Lu, F. Xue et al., "Towards the "third wave": an SCO-enabled occupational health and safety management system for construction," Safety Science, vol. 111, pp. 213-223, 2019.

[8] Z. Liu, T. Yang, N. Sun, and Y. Fang, "An antiswing trajectory planning method with state constraints for 4-DOF tower cranes: design and experiments," IEEE Access, vol. 7, pp. 62142-62151, 2019.

[9] W. Zhou, T. Zhao, W. Liu, and J. Tang, "Tower crane safety on construction sites: a complex sociotechnical system perspective," Safety Science, vol. 109, pp. 95-108, 2018.

[10] V. Mucenski, I. Pesko, T. Velkovski, J. Caloska, A. Vujkov, and D. Bibic, "Impact of construction machinery and tools on non-fatal injuries in the building processes," Tehnicki VjesnikTechnical Gazette, vol. 25, pp. 1680-1689, 2018.

[11] S. Kim, S. Kim, and D. Lee, "Sequential dependency structure matrix based framework for leveling of a tower crane lifting plan," Canadian Journal of Civil Engineering, vol. 45, no. 6, pp. 516-525, 2018.

[12] M. Al Hattab, E. Zankoul, and F. R. Hamzeh, "Near-real-time optimization of overlapping tower crane operations: a model and case study," Journal of Computing in Civil Engineering, vol. 31, 2017.

[13] A. Kaveh and Y. Vazirinia, "Optimization of tower crane location and material quantity between supply and demand points: a comparative study," Periodica Polytechnica-Civil Engineering, vol. 62, pp. 732-745, 2018.

[14] Z. S. M. Nadoushani, A. W. A. Hammad, and A. Akbarnezhad, "Location optimization of tower crane and allocation of material supply points in a construction site considering operating and rental costs," Journal of Construction Engineering and Management, vol. 143, 2017.

[15] T.-S. Wu, M. Karkoub, W.-S. Yu, C.-T. Chen, M.-G. Her, and K.-W. Wu, "Anti-sway tracking control of tower cranes with delayed uncertainty using a robust adaptive fuzzy control," Fuzzy Sets and Systems, vol. 290, pp. 118-137, 2016.

[16] J. Yoon, S. Nation, W. Singhose, and J. E. Vaughan, "Control of crane payloads that bounce during hoisting," IEEE Transactions on Control Systems Technology, vol. 22, no. 3, pp. 1233-1238, 2014.

[17] J. Vaughan, D. Kim, and W. Singhose, "Control of tower cranes with double-pendulum load dynamics," IEEE Transactions on Control Systems Technology, vol. 18, pp. 1345-1358, 2010.

[18] T. Bock, M. Nohmi, and M. Skibniewski, "Enabling e-business tools and robotics technology for teleconstruction," Autonomous Robots, vol. 22, no. 3, pp. 293-304, 2007.

[19] H. Liu and G. Tian, "Building engineering safety risk assessment and early warning mechanism construction based on distributed machine learning algorithm," Safety Science, vol. 120, pp. 764-771, 2019.

[20] D. H. Yun, J. Y. Park, and J. H. Kee, "Measures to reduce tower crane accidents during operation by improving signal system and education for signalmen," Journal of the Korean Society of Safety, vol. 34, pp. 68-75, 2019. 
[21] H. Chen and X. Luo, "Exploring the quantitative impact of localization accuracy on localization-based safety monitoring's performance on a construction jobsite," Journal of Computing in Civil Engineering, vol. 33, 2019.

[22] X. Luo, F. Leite, and W. J. O’Brien, "Location-aware sensor data error impact on autonomous crane safety monitoring," Journal of Computing in Civil Engineering, vol. 29, 2015.

[23] Z. Yang, Y. Yuan, M. Zhang, X. Zhao, Y. Zhang, and B. Tian, "Safety distance identification for crane drivers based on mask R-CNN," Sensors, vol. 19, 2019.

[24] F. N. Koumboulis, N. D. Kouvakas, G. L. Giannaris, and D. Vouyioukas, "Independent motion control of a tower crane through wireless sensor and actuator networks," ISA Transactions, vol. 60, pp. 312-320, 2016.

[25] G. Lee, J. Cho, S. Ham et al., "A BIM- and sensor-based tower crane navigation system for blind lifts," Automation in Construction, vol. 26, pp. 1-10, 2012.

[26] T. Cheng and J. Teizer, "Modeling tower crane operator visibility to minimize the risk of limited situational awareness," Journal of Computing in Civil Engineering, vol. 28, 2014.

[27] C. Klinger, "Failures of cranes due to wind induced vibrations," Engineering Failure Analysis, vol. 43, pp. 198-220, 2014.

[28] Y.-J. Park, S.-J. Cho, J.-W. Han, and S.-B. Shim, "Fatigue life prediction of planet carrier in slewing reducer for tower crane based on model validation and field test," International Journal of Precision Engineering and Manufacturing, vol. 18, no. 3, pp. 435-444, 2017.

[29] K. Yang, H.-S. Lee, M. Park, M. Jung, and S. Hwang, “A study of the tower crane hoisting time estimation simulation model with climate element for the high-rise building construction," Korean Journal of Construction Engineering and Management, vol. 14, no. 2, pp. 96-107, 2013.

[30] E. J. Lee and S. W. Shin, "Field survey on suitable in-service wind speed limit for tower crane operation," Journal of the Korean Society of Safety, vol. 33, no. 1, pp. 103-108, 2018.

[31] R. Miranda-Colorado and L. T. Aguilar, "A family of antiswing motion controllers for 2D-cranes with load hoisting/ lowering," Mechanical Systems and Signal Processing, vol. 133, 2019.

[32] M. H. El Ouni, N. Ben Kahla, S. Islam, and M. Jameel, “A smart tower crane to mitigate turbulent wind loads," Structural Engineering International, pp. 1-12, 2019.

[33] N. Sun, Y. Wu, H. Chen, and Y. Fang, "Antiswing cargo transportation of underactuated tower crane systems by a nonlinear controller embedded with an integral term," IEEE Transactions on Automation Science and Engineering, vol. 16, no. 3, pp. 1387-1398, 2019.

[34] D. M. Greenberger, M. A. Horne, and A. Zeilinger, "Multiparticle interferometry and the superposition principle," Physics Today, vol. 46, no. 8, pp. 22-29, 1993.

[35] W. H. Gage, D. A. Winter, J. S. Frank, and A. L. Adkin, "Kinematic and kinetic validity of the inverted pendulum model in quiet standing," Gait \& Posture, vol. 19, no. 2, pp. 124-132, 2004.

[36] S. Casalaina-Martin, D. Jensen, and R. Laza, "The geometry of the ball quotient model of the moduli space of genus four curves," Compact Moduli Spaces and Vector Bundles, vol. 564, pp. 107-136, 2012.

[37] D. Voisin, G. Grillaud, C. Solliec, A. Beley-Sayettat, J. L. Berlaud, and A. Miton, "Wind tunnel test method to study out-of-service tower crane behaviour in storm winds," Journal of Wind Engineering and Industrial Aerodynamics, vol. 92, no. 7-8, pp. 687-697, 2004.
[38] J. F. Eden, A. Iny, and A. J. Butler, "Cranes in storm winds," Engineering Structures, vol. 3, no. 3, pp. 175-180, 1981.

[39] M. A. Konerding, M. Bohn, T. Wolloscheck et al., "Maximum forces acting on the abdominal wall: experimental validation of a theoretical modeling in a human cadaver study," Medical Engineering \& Physics, vol. 33, no. 6, pp. 789-792, 2011.

[40] P. Pachera, P. G. Pavan, S. Todros, C. Cavinato, C. G. Fontanella, and A. N. Natali, "A numerical investigation of the healthy abdominal wall structures," Journal of Biomechanics, vol. 49, no. 9, pp. 1818-1823, 2016.

[41] M. Izquierdo, X. Aguado, R. Gonzalez, J. L. López, and K. Häkkinen, "Maximal and explosive force production capacity and balance performance in men of different ages," European Journal of Applied Physiology, vol. 79, no. 3, pp. 260-267, 1999. 